\title{
Risk Management and Quality Assurance Through the Food Supply Chain - Case Studies in the Swedish Food Industry
}

\author{
A. Olsson* and C. Skjöldebrand
}

Department of Design Sciences, Lund University, Sweden

\begin{abstract}
Processed food and eating out of the home are increasing phenomena, which presents new business opportunities for food manufacturers. However, the new food products require increased quality and safety, and thereby a more controlled distribution. The overall purpose of the research presented in this article is to describe the food supply chain from a critical context point of view in order to highlight the risks and the traceability issues. The paper expands previous discussions regarding critical control points into a critical context perspective in traceability in food supply chains. The initial part of the study is based on a literature review in the area of traceability combined with a number of related search words. A number of case studies have been carried out in order to map the food supply chains and better understand consumer standpoints. This paper describes how the system for distribution of food from manufacturer to end-user operates in Sweden. The chains studied all showed critical contexts. The paper suggests attitudinal changes towards overall supply chain responsibility, better resource utilisation and increased knowledge among actors. Furthermore it suggests supply chain actors to better integrate consumer insights on food safety perceptions in order to create value.
\end{abstract}

Key Words: Food supply chain, traceability, food safety, consumer value, case study.

\section{INTRODUCTION}

Food consumers want assurances that the food they buy and eat will be of the same high quality and safety when consumed as when manufactured. They want to be able to trust that the food they buy is safe, which means being able to trust the food companies along the food supply chain. However, at the same time the food industry is buffeted by head winds in many areas, such as with food "scandals" like the avian influenza, dioxin in chicken feed, mad cow disease, taste problems in Coca Cola etc. These problems show that the food industry has to deal with their product safety issues and create trust for the consumer $[1,2]$. The high risk exposure experienced by companies in quality assurance, will most likely affect their trademark, their market share, and their customers and consumers loyalty. While the direct effects due to a scandal or missed market opportunity hit the trademark owner, the indirect effects influence all actors in the supply chain. Consumer perception of food safety risk, for example, influences consumer attitudes and behavior in relation to food purchasing decisions. Thus perception of food safety risk has consequences for both consumer and producer welfare, and thereby for the overall food supply chain [3].

While food safety aspects have assumed high priority on the food producer agenda, the trend towards a more global food industry has created longer distances to transport the raw material, the ingredients and the finished products [4]. The consequence is that the food supply chains or networks become more and more complex. For the food industry it is, thus, important to implement systems for product safety and traceability in the entire network of actors. The underlying

*Address correspondence to this author at the Department of Design Sciences, Lund University, Sweden; E-mail: annika.olsson@plog.lth.se driving forces can be economical, to minimize recalls and keep market shares, but also strategic to protect trademarks and strengthen reputation. For the country, company and supply chain that shows that they can handle these new situations there will be completely new market opportunities. The free trading of safe products means a lot for the international market and contributes to the prosperity of human beings throughout the world. To ensure product safety, reduce risks and be able to respond when something happens require adequate risk sharing and handling as well as traceability handling and systems throughout the entire food supply chain or network. This is obvious to most actors in the supply chain, but the question is who will take the overall responsibility for implementing and maintaining such systems, when food is moved from one actor to another all the way to the end consumer? EU regulations stipulate that every actor in the food supply chain is obliged to know from whom they have received a product, what they have received and when it was received. In addition, they need knowledge of their outbound shipments in terms of what has been delivered, when it was delivered and to whom they have delivered it. However, since a quality problem affects each actor in the entire chain, increased awareness of all actors - including the consumer - is essential.

The overall purpose of the research presented in this article is to describe the food supply chain from a critical context point of view in order to highlight the risks and the traceability issues.

This overall purpose is divided into three sub purposes:

- to describe case studies that are used to exemplify and discuss the need for more knowledge, with suggestions for a proactive strategy of critical control context coupled to traceability and risk sharing for the described food chains' different actors, 
- to expand previous discussions of critical control points to a critical context perspective coupled to traceability, risk management and food safety in the food supply chains,

- to gain a better understanding of consumer perceptions of food safety in the supply chain.

The article is based on several case studies in the area of traceability and risk sharing in the food value chain.

\section{Demarcations and Definitions}

Supply chain management as well as traceability are both huge research areas that cover many issues and consequently have many definitions. Therefore the definitions used in this article as well as the demarcations made are provided in order to clarify the area covered by the research presented.

Chain traceability A relatively new area which is the consequence of a new EU regulation; It is traceability between companies and production units; could be between countries, and is related to the local traceability; standardisation necessary [5].

Internal traceability or local traceability Traceability of an internal production unit or a company; or within the same geographic area. Internal traceability is closely related to the internal systems for production, reporting and control; simpler than chain traceability [5].

Food value chain Porter [6] introduces a framework for systematically examining activities and their connection to competitive advantage, called the value chain in this case the food chain. Each step in a value chain adds value to the product seen from a consumer perspective. This value chain can no longer be evaluated separately but is constantly competing with other value chains

Food supply chain Explains a similar framework of the actors in the steps that products take from raw material to consumed product. Contrary to the value chain, the supply chain does not take the value addition into consideration [7].

Track Like "the train track" down streams in the food chain to see why the problem occurred.

Trace Like "the Indian trace" up streams in the food chain to see what has happened

Transparency (about a material) Can let through light and permits looking through. From a supply chain perspective, we mean transparent information between actors.

Risk communication This is communication about the company's risks.

Risk management has its starting point in a wish to avoid damage, losses and interruption. It is aimed at finding serious risks.

One demarcation made in this research is that the supply chain in the case studies has a geographic limitation: these studied supply chains all include actors within the same country.

\section{RESEARCH METHOD AND DATA COLLECTION}

A research project called "Traceability: a way to achieve transparency in the food chain" about traceability in the food chain has been carried out since 2003 [8]. The research pur- pose has been to develop a transparent value chain by the use of different methods and models. The different studies within the overall project were initiated mainly due to the consequences of new regulations on traceability of food and due to limited knowledge of consumer trust. Within the overall research project, two studies focusing on local operative risk sources and critical context in the food supply chain have been carried out $[9,10]$. In addition three related studies focusing especially on risk assessment of the food supply chain of chilled food have been completed [11,12,13,14,15]. The last study [16] was made to focus on consumer understanding and consumers perception of trust with regard to food safety.

The results presented have been analysed to find a holistic view on the traceability and risks in the whole value chain and are based on the above-mentioned studies on traceability and food safety in the food supply chain, carried out by a team of researchers.

An initial literature review of previous research in the area of traceability and logistics has also been made. The words traceability and logistics were combined with a number of related search words. The words combined with traceability were logistics (11); supply chain (31); safety and food (42); quality and food (38); ingredients (13); parts (34); software and food (7); The words combined with logistics were, trace (21); track and RFID (21); track and transport (8); RFID and food (9); quality and retail (20); quality and food (22); safety and retail (5); safety and food (19). The numbers indicate the number of relevant hits in the literature search, and the number of publications studied in the review. The literature review reveals a diffuse and rather overlooked research area.

The independent qualitative case studies, in the research project, were carried out with the aim to analyse the Swedish food supply chains in general, and chilled or sensitive food supply chains in particular. The reason for selecting the chilled food chain is the higher risk exposure due to the higher sensitiveness of chilled food compared to frozen and ambient food. According to Ellram [16] case studies focus on situations in real life settings with a set of relevant boundaries as the supply chains examined in this study. The input for analysis in the case studies was based on interviews with and observations of respondents from major actors throughout the supply chains in the Swedish food industry. The supply chains represent both the consumer retail sector and the food service sector. Case studies emphasise understanding the phenomenon studied, and stress an interpretive approach [17], which is suitable for this study since little previous research and written material can be found in the area of critical points and critical contexts regarding quality handling and safety in the food supply chain. The selection of respondents was based on the role they played in the supply chain of food from production to consumption. The aim was to obtain as wide a range of input as possible, which is why respondents from different actors at different levels in the company hierarchical were chosen. To understand consumers' opinions about food safety and their interaction with the food value chain an additional study was made where consumers were interviewed with regards to food safety, consumer loyalty and trust in the food value chain [15]. 


\section{FOOD SUPPLY CHAIN AND THE CRITICAL CON- TEXTS}

A food supply chain is complex, time-critical and dynamic. Typical steps of actors in the food supply chains are consumers, retailing or food service/catering, wholesaling, transporting, manufacturing and agriculture as illustrated in Fig. (1). The food supply chain management typically involves flows of products as well as the flow of information throughout the chain, to balance product movement with demand management [7]. The physical flow typically goes in one direction from the producers to the consumer, while the demand information flow has the opposite direction. The communication and relation flow is rather two-directional. With all these types of flows one can consider the interchanges between the different actors as contexts with several critical parameters involved. Therefore, previous research focusing only critical points is not considered to be sufficient, since all parameters of physical, informational and relational flow need to be integrated to a context.
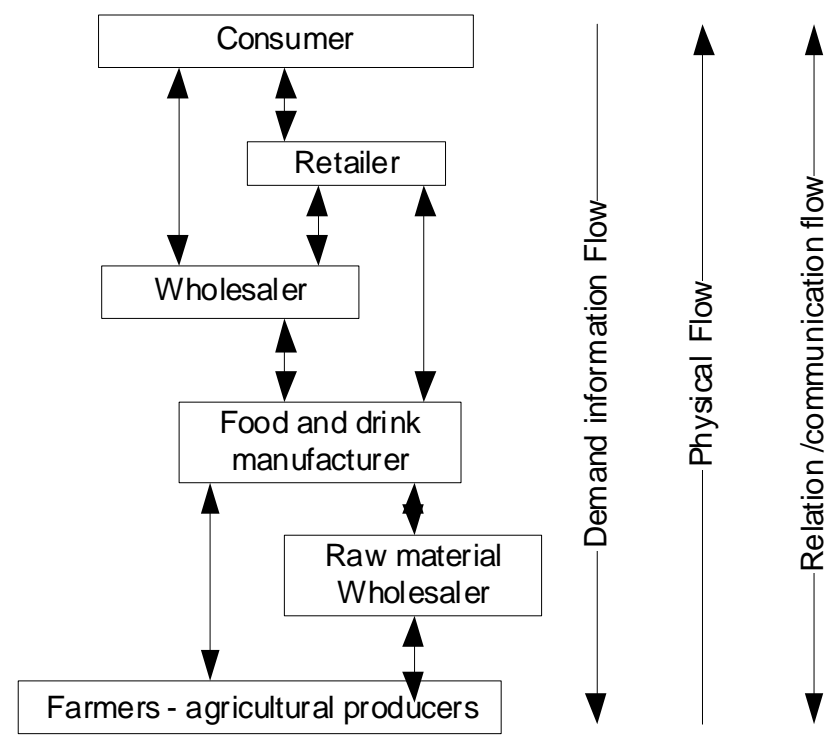

Fig. (1). A generic food supply chain, based on a scheme from Bourlakis et al. [4], with contextual parameters.

The food supply chain is complex and challenging. The complexity and time factors are more critical for chilled food than for frozen and ambient equivalents, since chilled foods require both higher speed due to shorter shelf life and better product integrity due to safety issues and quality at the point of consumption [18]. The two most important factors concerning the shelf life of a product are time and temperature. Most of the deteriorating changes that take place in food are temperature dependent and occur at a slower rate at lower temperatures [19]. For most chilled food products the optimal and recommended temperatures are under $+4^{\circ} \mathrm{C}$, while the temperatures required under law for many food products are higher $\left(+8{ }^{\circ} \mathrm{C}\right.$ in Sweden). When temperature is infringed upon, the shelf life is affected leading to an uncertainty of the quality and food safety. This means that even though products are stored at the legally stipulated temperatures, they might still lose quality quicker than when stored at the recommended temperatures [11].
Chilled food is sensitive and within the segment, prepared food is identified as being more critical from a quality perspective since the food is based on a mixture of different ingredients and is often cut into thin slices, which provides larger surfaces and thereby greater exposure to microorganisms. Meanwhile, the market demand for these products is constantly increasing as well as the variety of ingredients [20]. Furthermore, the increasing number of food scares in Europe has resulted in an interest in the origin of the food we eat together with the tracing of the food product throughout the food chain [21]. Consumers' demand for food safety and quality is an important issue today. In the distribution of chilled food in Sweden, all businesses that involve any kind of professional food handling are, according to law, obliged to supervise this activity in order to prevent health risks. Good relationships with distributors can result in better supply chain performance and, consequently, safer and betterquality food.

\section{EU Food Safety Regulations}

The commission of the European Community issued its "White paper" on food safety in the year 2000. This says that an independent authority shall be established, i.e. European Food Safety Authority (EFSA), and that standards on food safety "from farm to fork" shall be established. It also says that feed and food companies have primary responsibility for food. Further it says that the member states have to control these companies, and that the commission, by audits and inspections, has to supervise and control how the member states control systems works. There are also rules on recall and responsibility on food and feed products.

The regulation No 178/2002 of the European Parliament [22] and of the council of 28 January 2002 lays down general principals and requirement of food laws establishing the European Food Safety Authority and laying down procedures in matters of food safety. This came into force in February 2002.

Several of the articles concern traceability along the whole food value chain. Articles 14-20 which deal with traceability came into force 1 January 2005.

Article 3 in the regulation defines traceability as "the ability to trace and follow food, feed, food-producing animals or substance intended to be, or expected to be incorporated into a food or feed through all stages of production, processing and distribution"

Article 18 deals with traceability, and it says that "the traceability of food, feed, food-producing animals, and any other substances intended to be, or expected to be, incorporated into a food or feed shall be established at all stages of production, processing and distribution".

Article 17 deals with responsibility, and says that the companies have to ensure that food and feed satisfy the requirements of the food law.

The EU regulation on food safety demands that companies should focus more on the supply chain, and the legislation says that it is important to take into account "from farm to fork". This legislation does not cover what happens after the retailer has sold the product to the consumer. It also only covers "one step backwards" and "one step forward". Re- 
sults from several projects indicate the consumer perspectives of the food value chain were largely missing in the research on traceability and food safety, although the consumer is the part of the chain that evaluate the added value to the product that is produced. Therefore we established a new angle of our traceability research, and focus on trust relationships, perceived risk [15].

\section{TRACEABILITY IN CRITICAL CONTEXTS - FIND- INGS FROM THE STUDIES}

A recent literature study [23], reveals that previous research in the area of food safety and traceability is focused on local risk management, and internal traceability only, i.e. within one company. The studies reported have only focused on the connection between one or two operators and not on the whole supply chain. It is therefore impossible to analyse and evaluate benefits of increased traceability and supply chain risk handling in an entire system or an entire supply chain. Results from the case studies carried out in our research further show that there are several problems coupled to risk sharing along the food supply chain, especially in the interfaces between actors. One of the foremost problems is that the different participants use different systems that do not communicate automatically and in many cases cannot be connected to each other, i.e. connectivity issues in interfaces. Common information systems are also asked for by for example Sioen et al. [24]. It is instead routines, and the people that transfer information between the systems that are the main communication tools. This increases the risks of data that are manipulated and distorted, unintentionally or intentionally. To obtain accurate data that can reduce risks, physical and information flows must function especially in the interfaces between actors, and relationship aspects in these contexts must be considered. Hence, relationship aspects and information transfer becomes critical considerations [9]. From a relation point of view, the knowledge about what is happening in these interfaces and points for transfer is limited. It is therefore very important to study these interfaces from a connectivity and risk sharing point of view. This further leads to consequences that put consumers at risk and by extension, to economic risks for the brand name owners.

\section{Critical Points and Contexts in the Food Supply Chain}

The presence of traceability contributes to an increased transparency throughout the food supply chain. The traceability system can be considered as one part of a quality assurance system in which for example HACCP and risk assessment are included. According to Opara and Mazaud [25] traceability adds value to the quality assurance system by providing the communication linkage for identifying, verifying and isolating sources and products intervening with quality aspects.

To obtain full traceability and thus get better quality control in the food chain, it is important to analyse the entire chain trying to localize and identify the weak points. Zadernowski et al. [26] present an approach, the Polish Meat Traceability Critical Control Point analysis (MTCCP), which is an extension of HACCP principles to identify critical control points in the Polish meat industry. A critical control point can be e.g. origin and health of animals, HACCP plan of feed production, GMP of entering the pigsty, GMP of feed stocking. This approach can be further developed to find more general ways to analyse a food chain reaching from farm-to-fork and fork-to-farm [9,27,28]. By coupling chain traceability to the chain traceability control points, the basis for a system for quality control of the total food chain will be achieved

One aim of the entire traceability research project is thus to develop methods and systems to identify and evaluate different critical control points - Chain Traceability Critical Control Points (CTCCPs) along the whole food value chain from fork to farm. These points are the basis for quality assurance/quality control in the entire value chain. However, to connect the points throughout the entire chain, and to achieve transparency between the actors, require more than just identifying the critical points. It requires the context of integrating physical, information as well as relational flow between all actors in the supply chain or network.

When it comes to relations between the different actors in the supply chain, the knowledge about the other actor is limited. The decision processes are often controlled by the company that is strongest and often not focused on the supply chain as a whole. Profits, costs and risk sharing are limited. As Christoffer [29] stresses this is something that has to be changed in the future to add value and reduce risk for the individual product.

\section{The Swedish Food Supply Chain}

Based on input from the case studies of mapping Swedish food supply chains, the Swedish food industry can be characterised as having many producers, very few wholesalers and many retailers. The producers deliver to all wholesalers (Axfood, ICA and COOP), while the wholesalers deliver to a few retailers only (Fig. 2). In most cases, the deliveries are regulated by the relationship between the wholesaler and the retailer, where the wholesaler and the retailer in Sweden are often under the same umbrella of companies.

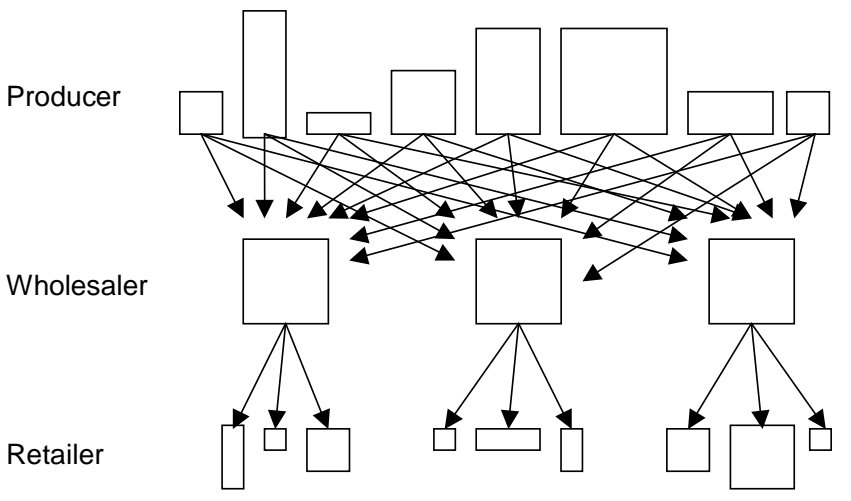

Fig. (2). Principle description of flow from food producers to retailers in Sweden.

The major difference between retail and foodservice supply chains (i.e. chains that supply restaurants and large-scale households) is that in the latter, the customer (e.g. the restaurant) is not obliged to purchase from one wholesaler or supplier. With so few wholesalers in retail and in food service, however, the power in the supply chain is mainly with the wholesalers. The responsibility for product quality and safety at the point of consumption, though, is with the manufacturer, in the sense that consumer claims are directed to the 
product owner. For private labels this is different, and the responsibility is with the retailers who own their own brand name.

Prior to entering into the results of the mapped chains of commercial actors in the studies, the results from the consumer study will be presented in order to compare consumer insights with the findings from the other actors in the food supply chain.

\section{The Aspect of the Consumer in the Food Supply Chain}

The consumer insights about trust, loyalty and food safety are found to be important input to the food chain actors and a kind of knowledge that at present is not well grasped by the actors. One main result from the study on consumer interaction in the food supply chain is that "trust" in the retail store and food manufacturers' brands is one of the main concerns among consumers [15]. Beside this main component of trust, the research has identified the supporting parts of consumer thinking regarding food safety as: degree of self-confidence in their own food preparation; degree of food refinement and processing by the producer; ethical and environmental concerns; hygiene in production and handling of products; taste as a quality indicator. The overall trust of the consumer for the retail store and food manufacturers' brands is based on consumer values and the interactivity between the consumer and the parties of the food value chain.

The consumer study shows the importance of understanding consumer values and the sense of belonging is related to the consumers' chosen lifestyle [15, 30]. The opportunities to develop 'ethical values' in the value chain has to some extent been explored by involving 'ethical values' in a societal perspective regarding the environmental [31] and social aspects [32]. The value development in the area of food safety and trust relationships, as demonstrated in the research, is to a large extent driven by ethical areas, environment, health and social ethics. This strategy developed by the food value chain is referred as Corporate Social Responsibility (CSR) [33]. The idea of companies becoming good corporate citizens is described by Barrett [34], where the involvement of corporate values is a natural ingredient in corporate management.

The research demonstrates that the food value chain does not create value on its own initiative, but is forced by the consumer to deliver solutions in accordance with individual consumers' chosen lifestyles [15]. Food and retail companies that do not adopt the current line of this business will be excluded from the food value chain. Accordingly, all identified parties of the food value chain (retail, food industry, farmers and ingredient suppliers) need to cooperate in order to ensure that the requested solution to a consumer demand is addressed.

\section{The Aspect of Other Actors in the Food Supply Chain}

As mentioned earlier the mapping of the food supply chains in the case studies has mainly been carried out in the chilled food chains because the potential risks are higher for chilled food than for frozen or ambient equivalents. The results of the case studies indicate that there are deficiencies in

Table 1. Critical Areas and Concerns

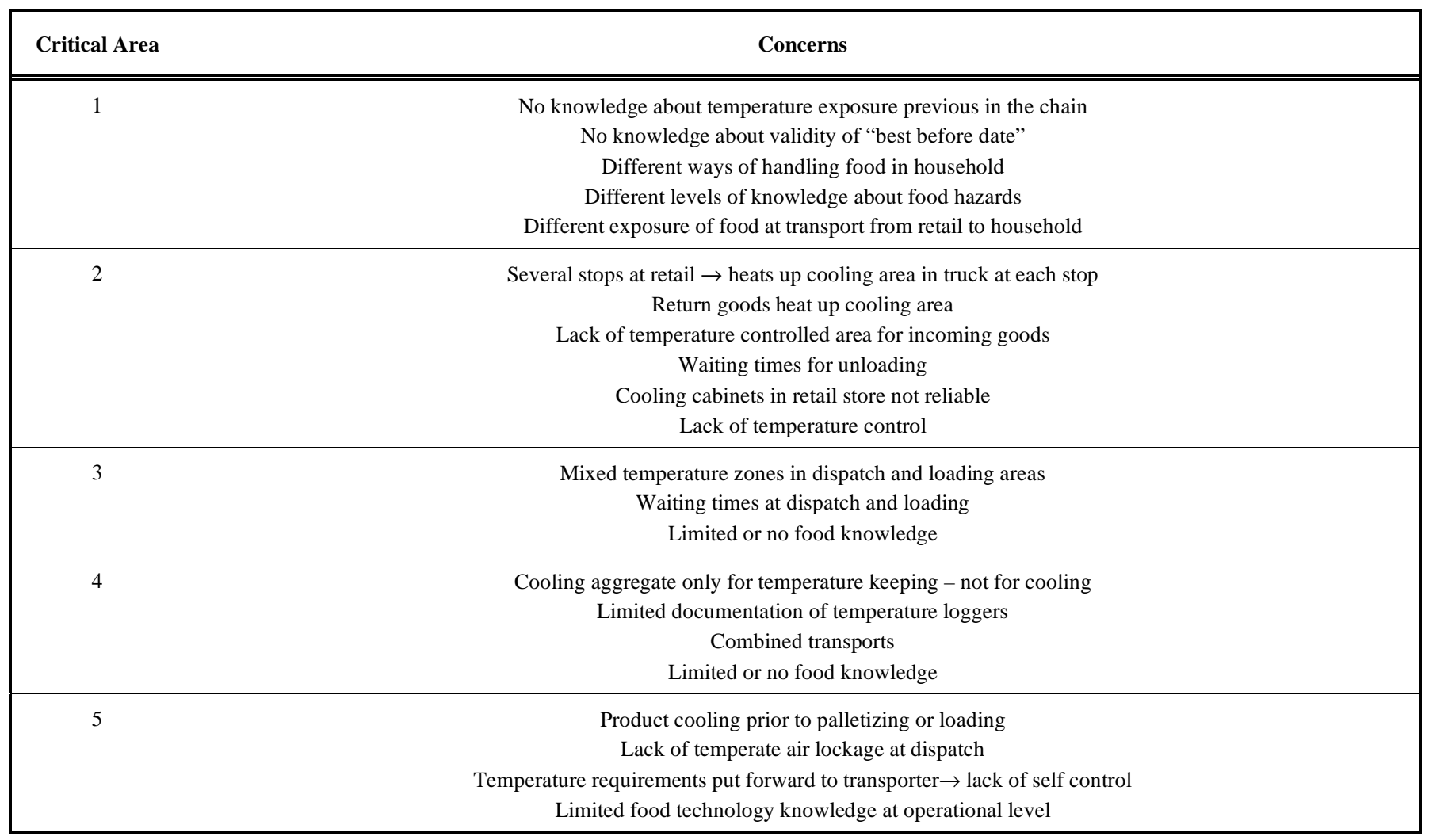


the supply chain for chilled food in Sweden in the area of temperature control but also in other areas that are valid also for frozen and ambient supply chains. Government reports confirm this and point out that temperature related problems occur throughout the entire chill chain among all actors, large and small. Critical points in terms of temperature handling were also identified throughout the entire chain in the case studies, both in the internal logistics of each actor and in the interconnections between actors. The major problems, however, occurred inbound and outbound from the different actors, i.e. in the shift from one actor to another. To include the relations and manual handling between actors to the critical points identified, five critical contexts are marked in the generic supply chain illustrated in Fig. (3) and the issues are summarised in Table $\mathbf{1}$.

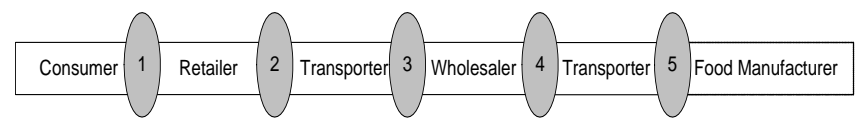

Fig. (3). Generic food supply chain.

The critical contexts in general and for temperature handling in particular, for each actor are described in more detail under specific headings following Table $\mathbf{1}$.

\section{The Retailers}

The retailer is the last professional actor in the chain and the one that suffers from for example accumulated temperature mistreatment in the chilled food chain. Reception of food in retail is very often taken care of by the transporters. In some cases the driver even puts the product on the shelf or in the chilled cabinet in retail stores.

Critical issues from chilled food point of view in retail are lack of temperature-controlled areas for incoming goods and the handling of food products outside of temperate areas. Occasionally food is placed outdoors on a loading platform. Previous studies show that the retail display of chilled food is found to be the weakest link in the chain, with a wide variation in temperature from cabinet to cabinet [35]. According to Swedish legislation, monitoring of the temperature in frozen and chilled cabinets is the responsibility of each actor in the chain Yet, temperatures are very seldom monitored by retailers; they usually entrust this to prior actors in the chain.

\section{Wholesalers}

In the food supply chains, the trend is that more and more food is delivered by wholesale dealers rather than by producers. At the same time the wholesale dealers are centralising their distribution locations so that transport distances are increasing. Longer distances and more requirements from the wholesalers will put more pressure on the transporters.

In general the studies indicate that the wholesale dealers are professional in food handling and in temperature control of incoming food. However, the temperature instrument used was identified as easy to handle for large amounts but difficult to handle in a correct manner. Negligence in documentation was also identified. The wholesalers have temperature zones both at reception and at dispatch; the only concern is that one temperature does not satisfy the need for all product categories.

\section{The Restaurants or Large-Scale Households}

Restaurants and large-scale households in Sweden receive all food via combined transports with frozen, cold and ambient food in the same transport. This is seen as positive since it reduces the number of deliveries to each restaurant. However, from a food quality perspective a combined transport affects shelf life since it is a compromise for certain food categories.

Modern cooking practices have made their entrance in catering kitchens. Cook-chill, sous-vide and cap-cold are all techniques for distributing chilled finished meals. Food cooked using these operations do not show the natural signs of bad smell and appearance when they deteriorate, which places new demands on food safety in the chill chain. The finished product should not be exposed to temperatures exceeding $3^{\circ} \mathrm{C}$, which is a problem since the chill chain in Sweden is based on a temperature of $8^{\circ} \mathrm{C}$ [11].

This study indicates that many restaurants and catering kitchens do not practice temperature supervision to a sufficient extent. This is due to insufficient knowledge, staff shortages and economic aspects. As a result, shortcomings are not revealed and no action is taken. This leads to health risks, reduced shelf life, quality problems and increased wastage. Deficiencies in the control function make it difficult or impossible for the various actors to pinpoint and put a claim for defective products to earlier stage in the chain [11].

\section{The Food Manufacturers}

As noted above EU regulation 178/2002 stipulates the producer's responsibility for quality assurance and traceability [22]. Each step in the food value chain has to know what is happening one step behind and one step ahead. It is worth remembering that it is often the food producer that is blamed when something upsets consumers when they buy a certain brand.

The study indicates professionalism among manufacturers in terms of maintaining temperature. However, some deficiencies in the cooling of products prior to dispatch, both with large and small manufacturers were identified. When palletising, for example, the centres of the pallets require long cooling time. In some cases manufacturers did not allow the product to reach the required temperature before palletising and dispatching. Some producers relied on the cooling aggregate in the truck to cool the products to the required temperature.

The study also indicates that there was a lack of temperature control at dispatch at the producer; only a few had air lockage at dispatch.

\section{The Transporters}

The study showed that the transports to large retailers are normally made in separate trucks for colonial, chilled and frozen food respectively, while food transports to smaller retailers are usually made as combined transports from wholesale dealers [11]. This means that food products with different temperature requirements were transported in the same vehicle. Multi-temperature zone vehicles were sometimes used, although this solution is expensive and custom- 
ers usually are not willing to pay for this [36]. At combined transports (different food categories in the same truck); a compromise of temperatures is made which has a negative effect on the quality of certain food products, i.e. those that are transported at a temperature other than the recommended one.

When it comes to transport cooling, no equipment, neither cabinets nor trucks, are made for cooling, but only for maintaining temperature. The transport refrigeration units do not have the capacity to cool products, which means that products with higher than required temperatures will increase the temperature resulting in a higher temperature in the truck than recommended. This is a critical issue since it was identified in the study that some producers rely on the transporters to cool the product to the required temperature. Another problem in the transports is to keep an even temperature in the cold compartment especially if there are many deliveries.

The study results indicate that there is a lack of temperature loggers and temperature controls are rare in this part of the chain. Previous studies also indicate that one third (1/3) of the chilled food in Sweden does not maintain the right temperature during transport even though speed and reliability of transports is of great importance since the shelf life for chilled products is limited. This study also indicates that limited knowledge of food technology and deteriorating processes may cause less suitable handling during transportation.

\section{SUGGESTIONS FOR IMPROVEMENT}

The results of this study show that the Swedish consumer might experience products with lower food quality than achievable, shorter shelf life than possible, more waste than necessary and in the worst case, health risks due to a combination of limited knowledge in all steps in the food supply chain and certain negligence in the food handling.

The following suggestions for more focus on certain areas are provided in order to improve quality, shelf life and food safety.

\section{Knowledge and Communication}

Throughout the entire line of business, most people are aware of deficiencies in the chilled food distribution. Knowledge is the foundation for understanding, accepting and thereby changing behaviour toward more control and safer handling throughout the chain. The majority of the personnel within the food supply chain have very little or no food technology training. Thus, step one in an action programme would be education.

\section{Resources}

The public authorities that are in charge of monitoring the distribution have lack the resources (money/time) to make adequate inspections. This places most of the responsibility on the food industry. The dilemma is whether to have full trucks, focusing economy, or the right temperature for every product, focusing quality. The temperature demands have to give way for economizing on transport costs, since quality losses also cost money. Investments in quality will result in longer shelf life, higher quality of the food products, and increased demand for the same products from the consumers. The longer shelf life also means less waste. An en- couragement for investment would be to identify and register cost of temperature related waste.

\section{Attitudinal Change}

A change in attitude towards supply chain thinking and collaboration is necessary. Today the participants in the supply chain rely on the next link, and lack of complaints is seen as a proof of an intact food chain. Participants want to optimise their part of the distribution and the driving force behind producers is to produce as much as possible whether it is eaten or thrown way. No one considers the whole supplychain and sub optimizing might be the result.

A pro-active mind set, where an overall control system with available data for all actors in the chain based on collaboration and shared responsibility can be one solution. By creating an organization of different actors, misunderstandings could be eliminated and knowledge and understanding of different problems in the chain could increase. Collaboration will also make just-in-time delivery in Sweden possible, which will improve the quality of fresh products and reduce waste. A code of practice as exists in the UK could be another element to improve collaboration.

When it comes to information, UK studies suggest that communication about food safety and food risks has to be conducted in an integrated manner with food industry, government and consumers [37]. This reasoning is also applicable in the Swedish study, where a lack of integrated communication is apparent.

\section{CONCLUSIONS}

The conclusions from ours studies are

- Most companies and actors in the supply chain fulfil the demands on traceability established by the EU regulations because these demands are at a minimum. This however, counts for the internal traceability and does not incorporate the chain perspective.

- The interchanges between the different actors of a food supply chain should be consider as contexts with several critical parameters involved based on the physical flow, the information flow and the relational flow. It is further the connectivity in terms of all these flows between actors that are identified as the week points in the supply chain

- From a relation point of view, the knowledge about what is happening in these interfaces and points for transfer are limited. It is therefore important to study these interfaces from a connectivity and risk sharing point of view. This further leads to consequences that put consumers at risk and at extension to economic risks for the brand name owners.

- Pro-activity means adding value based on traceability and risk sharing which in turn makes it necessary to add the consumer as a part of the food value chain

- Traceability, food safety and risk management are mostly focused on the technology and systems to be implemented and not on consumer safety, nor on relations between actors.

- The retailers have in general control over the supply chain by for example being the one that sells the prod- 
ucts to the customers but also by having their own labels and standards that they require for the producer to be a supplier

- The chill chain as general is very often lacking a holistic approach and a consequence of this is that the chain cannot fulfil the regulations to keep temperature below the required.

- Nobody in the supply chain has taken a holistic responsibility on the supply chain each actor acts on their own

\section{ACKNOWLEDGEMENT}

This work is financially supported by VINNOVA projects NGIL (Next Generation Innovative Logistics Centre) "Risk sharing through supply chain traceability", Innovations in Borderline project "Added value through risk manangement and traceability” and Mobile pipelines. It was also supported by the companies Tetra Pak, Skanmejerier and ABB and by NUTEK - The Swedish Agency for Economic and Regional Growth through its programme "Vägvinnare" Samverkan Högskola - SMF.

\section{REFERENCES}

[1] Nennery B, Fischler B, Boogaerts M, Lison D, Wellems J. The Coca-Cola incident in Belgium June 1999. Food and ChemTechnol 2002; 40:1657-1667.

[2] Olsen P. Tracefish presentation at seminar. Göteborg: Sweden 2003

[3] Yeung RMW, Morris J. Food safety risk: Consumer perception and purchase behavior. Br Food J 2001; 103; 3: 170-187.

[4] Bourlakis C. Bourlakis M. The future of food supply chain management. In: Bourlakis MA, Weightman PWH, Eds. Food supply chain management. Blackwell Publishing 2004; 221-230.

[5] Food Standard Agency. Traceability in the food chain. A study food chain strategy division. 2002.

[6] Porter M. Green and competitive: Ending the stalemate. Harvard Business Review Books 1995.

[7] Gustafsson K, Jönson G, Smith D, Sparks L. Retailing logistics \& fresh food packaging. Kogan Page Limited: London 2006.

[8] Skjöldebrand C, Lareke A. Traceability a way to achieve transparencies. Research project; Packaging Logistics: Lund University 2003.

[9] Eken C, Karlsson J. Livsmedelssäkerhet ur ett försörjningskedjeperspektiv. Master Thesis; Lund University 2006.

[10] Olsson D, Svensson S. DOSS - Värderingsmodell för riskerna vid tillverkningen av flytande livsmedel - En analys av interna risker och deras ekonomiska konsekvenser på produktens varumärke. Master Thesis; Lund University 2005.

[11] Björklund M. Distribution av temperaturkänsliga livsmedel, Master Thesis; Packaging Logistics: Lund University 2002.

[12] Karlberg M, Klevås J. Kylkedjan för livsmedel - en kartläggning av den svenska distributionen med fokus på temperaturbrister. Master Thesis; Packaging Logistics: Lund University 2002.

[13] Olsson A. Temperature controlled supply chains call for improved knowledge and shared responsibilities. Ed. Aronsson H. Proceedings of the NOFOMA Conference; 2004 Linköping; Sweden.
[14] Ousbäck C, Olsson P. Säkerställande av en obruten kylkedja vision eller verklighet. Master Thesis; Packaging Logistics: Lund University 2003.

[15] Lareke A. The Tyrannical Consumer. Licentiate Thesis; Packaging Logistics: Lund University 2007.

[16] Ellram LM. The use of case study method in logistic research. J. Business Logistics 1996; 17: 2: 93-138.

[17] Denzin NK, Lincoln YS. The landscape of qualitative research. Sage Publications: USA 1998.

[18] Taylor J. Recommendations on the control and monitoring of storage and transportation temperatures of medicinal products. The Pharm J 2001; 267.

[19] Hernandez. Food safety. Food Manage 2001; 36: 84-86.

[20] Smith D, Sparks L. Temperature controlled supply chains. In: The supply chain management for food. Ed. Bourlakis M. BlackwellPublishing: Oxford 2003.

[21] Manning L, Baines RN, Chadd SA. Quality assurance: a study of the primary poultry producers' perspective. Br Food J 2007; 109: 4: 291-304.

[22] EC Regulation No 178/2002 of the European Parliament and of the Council of 28th January 2002, (laying down the principles and requirements of food law, establishing the European Food Safety Authority and laying down procedures in matters of food safety).

[23] Nilsson F, Skjöldebrand C. Mobile pipelines. State -of -the art inom spårbarhet med fokus på logistik och stödsystem i försörjningskedjor. Research Report Mobile pipelines. Lund University 2006.

[24] Sioen I, Verbeke S, DeHenauw S, et al. Determining the Origin of Seafood Products on the Belgian Market: Challenges to Traceability and Database Management. Open Food J 2007; 1: 32-42.

[25] Opara LU, Mazaud F. Food traceability from field to plate. Outlook Agric 2001; 30: 239-247.

[26] Zadernowski MR, Verbeke W, Verhé R, Babuchowski AJ. Int Food Agribuss Mark 2001;124: 5-22.

[27] Alklint C, Göransson A. Spårbarhet en väg mot transparens Fallstudier i livsmedelskedjan. Research Report Lund University 2004.

[28] Nilsson F. Adaptive logistics - using complexity theory to facilitate increased effectiveness in logistics. Packaging Logistics: Lund University 2004.

[29] Christopher M. Logistics and supply chain management. $2^{\text {nd }}$ ed. Prentice Hall: London 1998.

[30] Lareke A, Skjöldebrand C. Value creation in the food supply chain by consumer trust and food safety. J Food Eng 2007 (submitted).

[31] Porter M. The competitive advantage of the inner city. Harvard Business Review Books 1995.

[32] Porter M. The Competitive Advantage. New York. Free Press. McMillan: London 1985.

[33] Cerne A. Integrating corporate social responsibility with marketing strategies in retailing. Doctoral Thesis; Lund University: Lund Business Press 2003.

[34] Barrett R. Liberating the corporate soul. Building a visionary organisation. Eds. Butterworth. Heineman. 1998.

[35] James S. The Chill Chain 'from Carcass to Consumer”. Meat Sci 1996; 43: 203-216.

[36] Ovesen M. Kvalitet på mattransporterna - vem bryr sig? (Quality in food transport - who cares?). Transport iDag/iTrafik 2004.

[37] Kuznesof S, Brennan M. Perceived risk and product safety in the food supply chain. In: Ed. Bourlakis M. The supply chain management for food. Blackwell: Oxford 2003.

(c) Olsson and Skjöldebrand; Licensee Bentham Open.

This is an open access article distributed under the terms of the Creative Commons Attribution License (http://creativecommons.org/licenses/by/2.5/), which permits unrestrictive use, distribution, and reproduction in any medium, provided the original work is properly cited. 